\section{Methotrexate and Trimethoprim-Sulfamethoxazole for Pneumocystis pneumonia Prophylaxis}

\section{To the Editor:}

We read with interest the recent article by Katchamart, et al ${ }^{1}$ about Canadian recommendations for the use of methotrexate (MTX) in patients with rheumatoid arthritis (RA). The authors conclude that trimethoprimsulfamethoxazole (TMP-SMX) should be avoided in RA patients treated with MTX. This recommendation was based on several case reports and a retrospective case-control study in which concomitant use of TMP-SMX and MTX was associated with blood dyscrasias ${ }^{1}$. In their cases, therapeutic doses of TMP-SMX were prescribed to treat urinary tract infection or other infectious diseases, but chemoprophylactic doses of TMP-SMX for Pneumocystis pneumonia (PCP) were not included. We believe that these 2 clinical indications for treatment with TMP-SMX should be considered separately. In fact, the contraindication for TMP-SMX use for PCP prophylaxis has been described as "outdated" in a recent review article ${ }^{2}$.

PCP caused by $P$. jirovecii, one of the serious opportunistic infections in immunocompromised hosts, has been reported in RA patients receiving low-dose MTX or combination therapy with MTX and tumor necrosis factor (TNF) inhibitors ${ }^{3}$. We previously reported the clinical characteristics of Japanese patients with RA who developed PCP during treatment with infliximab (IFX) and MTX ${ }^{4}$. Risk factors identified for PCP in RA patients receiving this treatment were age $\geq 65$ years, a daily dose of at least $6 \mathrm{mg}$ prednisolone, and coexisting pulmonary disease ${ }^{5}$. A metaanalysis suggested high efficacy for chemoprophylaxis with TMP-SMX against PCP in non-HIV-infected patients; the protection rate is almost $100 \%$ with adequate adherence and tolerance ${ }^{6}$. Because the incidence of PCP in RA patients receiving IFX and MTX in Japan is approximately 10- to 20-fold greater than that in Western countries, we recommended PCP chemoprophylaxis with TMP-SMX for those Japanese RA patients receiving IFX and MTX with the 3 risk factors described above ${ }^{4}$. The Japanese guidelines for the use of TNF inhibitors in RA patients were therefore amended, following our recommendation ${ }^{7}$.

Both $\mathrm{MTX}^{8}$ and $\mathrm{TMP}^{9}$ inhibit dihydrofolate reductase (DHFR), and SMX inhibits dihydrofolate synthesis ${ }^{9}$. It has been reported that TMP, as well as SMX, inhibited erythroid and granulocyte-monocyte colony formation in vitro, in a dose-dependent manner, and that this inhibition was reversed by folinic acid ${ }^{10}$. These data suggest that higher dosages of TMP-SMX administered with MTX lead to a stronger inhibition of folate metabolism and induce blood dyscrasias. The dosage of TMP-SMX for chemoprophylaxis of PCP is only one-fourth to one-eighth that used for treatment of urinary tract or skin infection (TMP $80 \mathrm{mg} / \mathrm{SMX} 400 \mathrm{mg}$ per day for PCP chemoprophylaxis vs $320 \mathrm{mg} / 1600 \mathrm{mg}$ or $640 \mathrm{mg} / 3200 \mathrm{mg}$ per day for treatment of urinary tract or skin infection). To date, no case of MTX-associated blood dyscrasias has been reported in RA patients receiving the chemoprophylactic dose of TMP-SMX for PCP. To study the safety of biologics in Japan, we have a large registry of RA patients (Registry of Japanese Rheumatoid Arthritis Patients on Biologics for Long-term Safety, REAL). In this registry, 46 of 1298 patients with RA received a chemoprophylactic dose of TMP-SMX for PCP concomitantly with MTX. Most of these patients were also given $5 \mathrm{mg} /$ week of folic acid. None of these patients developed MTX-associated blood dyscrasias over an average observation period of 1.16 years (range $0.5-2.5 \mathrm{yrs}$ ). Although 40 out of the 46 patients used biologics, none developed PCP. These data indicate that standard chemoprophylaxis with TMP-SMX for PCP can be safely used in RA patients receiving MTX.

Thus, therapeutic doses of TMP-SMX should not be used with MTX in patients with RA, but chemoprophylaxis for PCP with low-dose
TMP-SMX can be used safely with careful monitoring. The 2 clinical indications for treatment with TMP-SMX should be considered separately in RA patients receiving MTX therapy.

HAYATO YAMAZAKI, MD; TOSHIHIRO NANKI, MD, PhD, Associate Professor, Department of Pharmacovigilance, Graduate School of Medical and Dental Sciences, Tokyo Medical and Dental University, Department of Medicine and Rheumatology, Graduate School of Medical and Dental Sciences, Tokyo Medical and Dental University; NOBUYUKI MIYASAKA, MD, PhD, Professor, Department of Medicine and Rheumatology, Graduate School of Medical and Dental Sciences, Tokyo Medical and Dental University; MASAYOSHI HARIGAI, MD, PhD, Professor, Department of Pharmacovigilance, Graduate School of Medical and Dental Sciences, Tokyo Medical and Dental University, Department of Medicine and Rheumatology, Graduate School of Medical and Dental Sciences, Tokyo Medical and Dental University, Tokyo, Japan. Address correspondence to Prof. M. Harigai, Department of Pharmacovigilance, Graduate School of Medical and Dental Sciences, Tokyo Medical and Dental University, 1-5-45 Yushima, Bunkyo-ku, Tokyo, Japan. E-mail: mharigai.mpha@tmd.ac.jp

\section{REFERENCES}

1. Katchamart W, Bourre-Tessier J, Donka T, Drouin J, Rohekar G, Bykerk VP, et al. Canadian recommendations for use of methotrexate in patients with rheumatoid arthritis. J Rheumatol 2010;37:1422-30

2. Thomas CF Jr, Limper AH. Pneumocystis pneumonia. N Engl J Med 2004;350:2487-98.

3. Kaur N, Mahl TC. Pneumocystis jiroveci (carinii) pneumonia after infliximab therapy: a review of 84 cases. Dig Dis Sci 2007;52:1481-4.

4. Komano Y, Harigai M, Koike R, Sugiyama H, Ogawa J, Saito K, et al. Pneumocystis jiroveci pneumonia in patients with rheumatoid arthritis treated with infliximab: a retrospective review and case-control study of 21 patients. Arthritis Rheum 2009;61:305-12.

5. Harigai M, Koike R, Miyasaka N. Pneumocystis pneumonia associated with infliximab in Japan. N Engl J Med 2007; 357:1874-6

6. Green H, Paul M, Vidal L, Leibovici L. Prophylaxis of Pneumocystis pneumonia in immunocompromised non-HIV-infected patients: systematic review and meta-analysis of randomized controlled trials. Mayo Clin Proc 2007;82:1052-9.

7. Koike R, Takeuchi T, Eguchi K, Miyasaka N. Update on the Japanese guidelines for the use of infliximab and etanercept in rheumatoid arthritis. Mod Rheumatol 2007;17:451-8.

8. Jolivet J, Cowan KH, Curt GA, Clendeninn NJ, Chabner BA. The pharmacology and clinical use of methotrexate. N Engl J Med 1983;309:1094-104.

9. Petri WAJ. Sulfonamides, trimethoprim-sulfamethoxazole, quinolones, and agents for uninary tract infections. In: Brunton LL, Lazo JS, Parker KL, editors. Goodman and Gilman's the pharmacological basis of therapeutics. New York: McGraw-Hill Inc.; 2006:1111-9.

10. Golde DW, Bersch N, Quan SG. Trimethoprim and sulphamethoxazole inhibition of haematopoiesis in vitro. Br J Haematol 1978;40:363-7.

J Rheumatol 2011;38:4; doi:10.3899/jrheum.100858 